\title{
CONTROLLING OF GEARBOX LUBRICANT VOLUME FOR A GEAR TEST RIG
}

\author{
Thiago Neves Cunha \\ Technological Institute of \\ Aeronautics \\ São José dos Campos, São \\ Paulo, Brasil
}

\author{
Ronnie Rodrigo Rego \\ Technological Institute of \\ Aeronautics \\ São José dos Campos, São \\ Paulo, Brasil
}

\author{
Anderson Vicente Borille \\ Technological Institute of \\ Aeronautics \\ São José dos Campos, São Paulo, \\ Brasil
}

\begin{abstract}
The lubricant oil in experimentation of gear performance is highly influent on the tests results. This paper carries out a pump system control strategy to control the lubricant volume inside a gearbox of a test rig. Back-to-back test centers consist of one or more pairs of gearboxes connected back-to-back, what allows recirculation of mechanical power. These tests rigs are used to test fatigue life and efficiency of gears. The back-to-back rigs are made meeting standards requirements, which increase the reliability of results comparison between different sources. In fatigue life experiments, pitting and micro-pitting failures modes are highly sensitive to lubricant variations, due the oil capacity of decrease friction. The lubricant volume inside a gearbox also has high influence in efficiency, once high-volume levels relate to increased inertia and churning losses. Worldwide back-to-back tests rigs use constant oil volume in the gearboxes and controls the temperature inside the boxes. Once the back-to-back test rig presented in this paper has outside temperature control, due performance, two pumps are used to control the lubricant volume inside the gearboxes. This system has non linearities related to the motor pump torque response and the inside geometry of the gearboxes. With the objective of controlling the oil volume inside the gearbox, a Proportional Integrative Derivative (PID) controller was implemented to one hydraulic pump's motor. It is defined ranges and limitations in the pump system operation to maintain the oil propagation in a linear relation to frequency regime. Using empiric experimentation, the PID parameters are defined. By controlling different oil volumes under the influence of different gear rotational speed, the controller has proved effectiveness by maintaining linear relation oil propagation and the volume variation inside the maximum permissible. The results leveraged the test rig to a high-precision level of torque efficiency and contact fatigue assessment in gears.
\end{abstract}

Keywords: control system, PID, gear lubricant, torque efficiency

\section{INTRODUCTION}

In gears characterization and testing, the studied parameters, as geometries, material and lubricant oils, are quantified and qualified by analyzing the propagation of different failures modes. In oils lubricant analyses, the most sensible variable failure mode to the oils properties is the pitting and micropitting, which are highly connected to the sliding speed between a geared pair of gears. The oil has the function of dissipate temperature and decrease friction losses. In other hand, higher the oil amount, higher are the losses related to the lubrication excitation, and consequently, less is the transmission efficiency. In gear testing, there are standards with the objective of increase the reliability of experiments comparison between different test centers sources. Between the requisites for pitting test, the oil volume must be constant during the testing and must be maintained at the center of the tested gear [1]. Although, there are researches has [2] which pursuit optimum efficiency by searching the best relation between efficiency and temperature dissipation and lubrication. This work carries out a PID controller to control the oil volume in transmissions boxes. Enabling the test center to perform pitting fatigue experiments and test influence of lubricant oil in the gear's performance.

\section{PROBLEM DESCRIPITION}

The back-to-back center utilized is made by four transmission boxes with distance between center of axis $71 \mathrm{~mm}$ and $114 \mathrm{~mm}$. The Figure 1 presents the structure of the test centers and the boxes used for gears testing. 


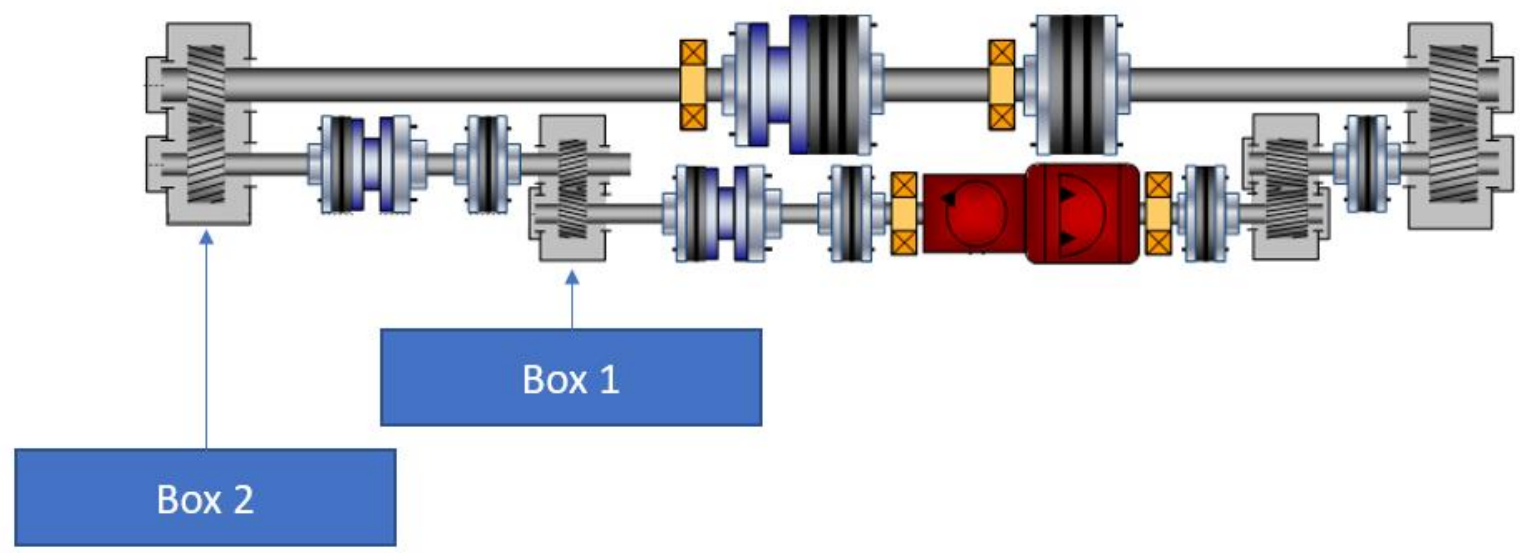

Figure 5 - Test rig overview and testing boxes. Box 1 is the used box.

Meeting the standards, the gear box with the tested gears must has a constant volume of lubricant oil. Besides the oil lubricant volume, the temperature also must be controlled. Therefore, the major back-to-back rigs, as the test rigs of $[3,4]$, use resistors and cooling coils within the transmission boxes. In the presented test center, the strategy is different. The oil is heated or cooled in a machine outside the boxes, which due its volume (size proportional to potency), would not fit in the transmission boxes. During the experiments, the temperature must be alternated several times, between standard test temperature and temperature of inspection.

Although there is no standardization of the maximum variation value of the oil lubricant volume within the transmission boxes, it is usual to complete the oil amount between inspections stops. There is a tubular visor (Figure 2) installed to the boxes to visual monitoring, once the box in complete sealed. Based in the mean losses between the inspections of the used test center, it was possible to identify a maximum variation, through an external tubular visor, of $3 \mathrm{~mm}$ (approximately to 46,96 milliliters, from the gear's center height). In the same way, there is no standardization of the maximum time to the stabilization of the oil lubricant volume inside the transmission boxes. As a reference, it is utilized the medium time of an operator completing the oil lubricant in non-controlled oil volume boxes.

The oil is inputted in the box through the superior plate and the oil is pumped out via the lowest level inside the box. All boxes are equipped with outside tubular visors to visual inspection and sensor measurements. The Figure 2 presents the box number 1 , its outside view and cutting inside view.

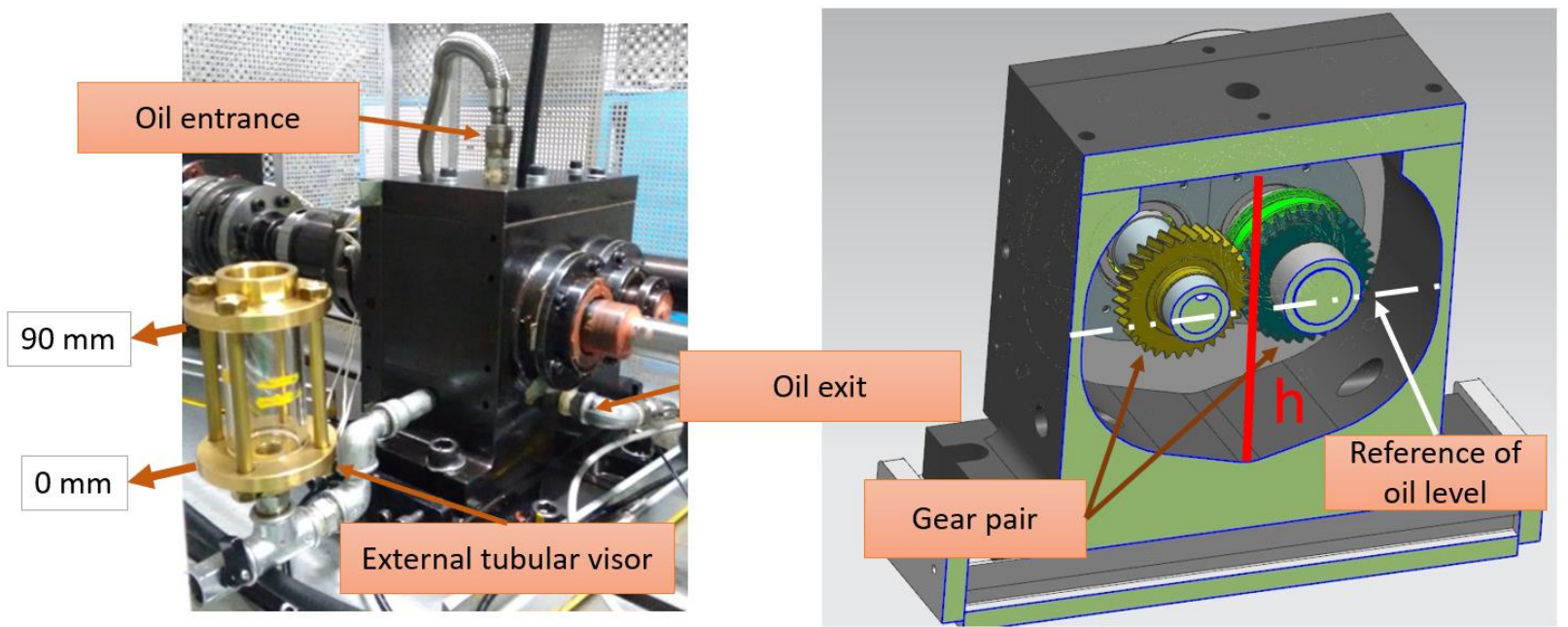

Figure 6 - Transmission box structure: entrance and exit oils points, tubular visor range reference and inside box

The oil transport between the external temperature control unit and the boxes is made by using of two pumps. The first one pumps the oil towards the box inside and the second one pumps out the oil. Both pumps work with triphase inductive motors of power of approximately $4 \mathrm{~kW}$. The motors are controlled by two frequency inverters and has variation of torque available as a function of speed, as presented in Figure 3. 


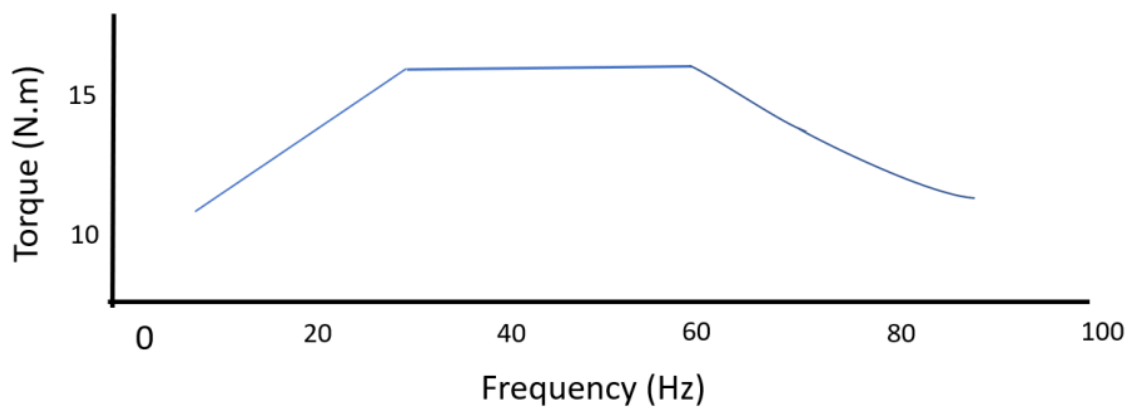

Figure 7 - Frequency/Torque relation from inductive motor and inverter set

From the experiment requirements to gear testing and the observations made, it is defined as requirements to the control system: maximum variation of $\pm 3 \mathrm{~mm}$ of oil level and stabilization in $0,5 \%$ of the total experiment period $(\sim$ 6 minutes).

\section{MEASUREMENT SYSTEM}

The measurement is done by measuring the oil level in a tubular visor presented in Figure 2. Due angles and short sections of the connections between the box and the visor, the kinetic energy inside the visor is smaller. Although it induces delay in the equilibrium of the levels of inside and outside the box, the variation is small enough to be inexpressive when compared to the maximum allowed variation.

The reference $\mathrm{o} \mathrm{mm}$ to the control system is the visor's base and it is increased up to $90 \mathrm{~mm}$, in the up face, as presented in Figure 2.

\section{CONTROLLER}

It is supposed that there is a constant flow in the transmission box entrance. It is analyzed the oil level " $\mathrm{h}$ " measured through the time, of the box's base to the box's top (Figure 3). Due the inside geometry of the box, the level increasing would not present a linear behavior. Furthermore, the torque response of the ensemble motor and frequency inverter is not linear as well. These two characteristics of non-linearities make that a PID controller does not be am optimum option to this application [5].

By limiting the motor's speed inside the torque zone which generates linear proportional flow variation (10 Hz to $30 \mathrm{~Hz}$ ), although decrease the range of controller's response, guarantee the robustness of the available operational zone. Despite the inside area of the box variates over the box's height, for the volume which comprehends the gear pair, the area is constant.

The pump which pull out the oil from the box is set to a constant flow, while the entering oil flow is controlled. The proposed controller is limited in regardless of the zone with minimum torque to achieve constant flow, besides, it is defined a minimum speed of $10 \mathrm{~Hz}$, equivalent to a command voltage of $4 \mathrm{~V}$ to the frequency inverter, to the entrance pump oil. The minimum speed guarantees that there is no non-linearities in the oil supply, due the nonlinear torque availability, which could generate more controlling instability. The controller is a parallel PID controller with gains defined empirically to robustness in the working zone. The controller output is a voltage between $\mathrm{o}$ and $10 \mathrm{~V}$ and there is a limiter in the error integration as a measuring of safety. The exit pump keeps the flow constant and its speed is superior to the minimum speed of the entrance pump.

\section{TEST PARAMETERS}

Regardless the validation of the controller in transient regime, there were defined 3 levels of oil to be maintained for a short period. These levels are respectively: $20 \mathrm{~mm}, 40 \mathrm{~mm}$ and $80 \mathrm{~mm}$. In the validation of the controller during the experiments, it was defined $60 \mathrm{~mm}$ (gears center) and the speeds where referenced by the real experimentation speed, it is: $2250 \mathrm{rpm}$ for pre-testing and 3500 rom for testing.

\section{RESULTS}

The PID parameters where defined empirically to achieve maximum variation of $\pm 3 \mathrm{~mm}$ of the oil level and maximum stabilization time of 6 minutes. The Table 1 presents the achieved parameters. 
Table 2 - PID's parameters

\begin{tabular}{c|c}
\hline Controller's fractions & Gains \\
\hline P & 0,140 \\
I & 0,008 \\
D & 0,000 \\
Limiter I (mm) & 5,000 \\
\hline
\end{tabular}

\section{Pump Frequencies Strategy}

To maintain the pumps working in a linear regime, the exit pump was fixed in $25 \mathrm{~Hz}$ and the entrance pump with a minimum of $10 \mathrm{~Hz}$ and maximum of $30 \mathrm{~Hz}$.

\section{Oil Level for Non Rotational Scenario and Rotational Scenario}

From the graphic of Figure 4, it is possible to identify the stability of the oil level afterwards the transient period. It is also possible to identify the doubling of the overshooting between the $20 \mathrm{~mm}$ and $40 \mathrm{~mm}$ levels, although a less expressive difference between $40 \mathrm{~mm}$ and $80 \mathrm{~mm}$. The fact that the time evolution of the oil levels, from the $\mathrm{o} \mathrm{mm}$, is like a straight line, represents that the pumps are working in a linear proportional to speed regime and the nonlinearities due volume variation are not so relevant.

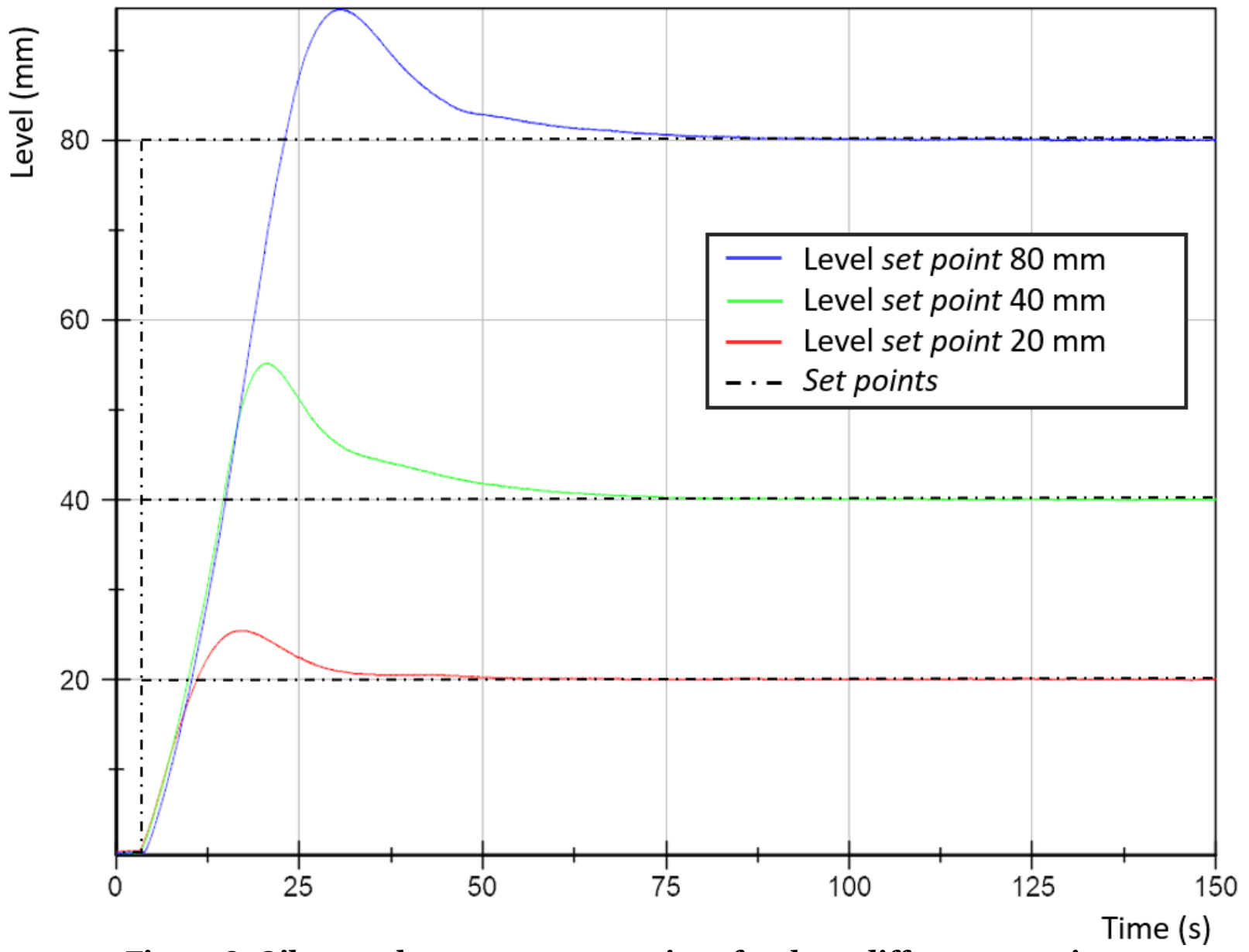

Figure 8: Oil control responses comparison for three different set points

The variable which most influences the oil turbulence inside the transmission box and, consequently generates instability to the controlling, is the gear speed. To validate the controller performance in a rotational scenario and the speed influence, the graphic in Figure 4 presents the comparison of the controlled oil level under the influence of three different speeds. 


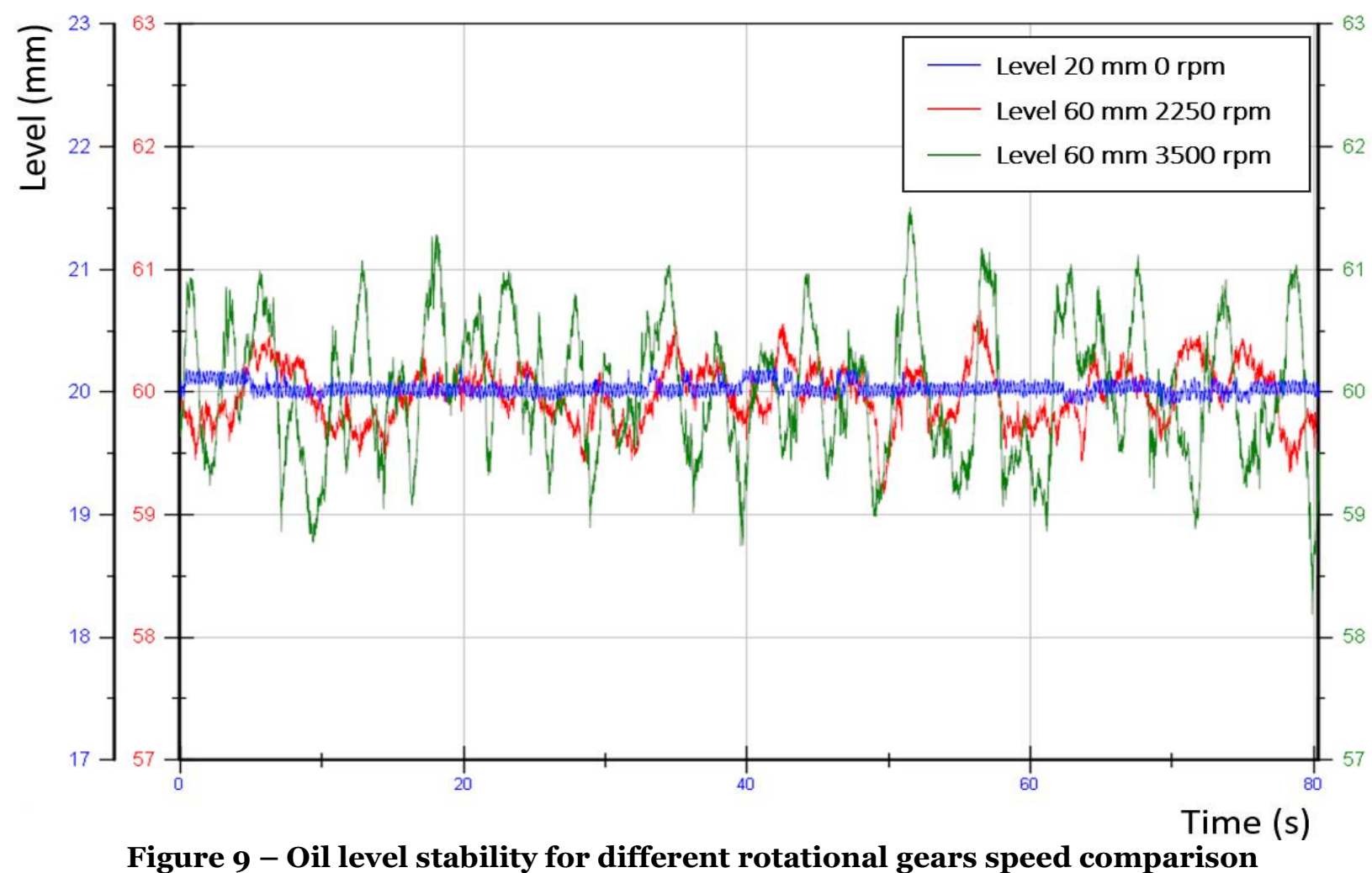

\section{CONCLUSION}

From the temporal evolution of the oil level of three different set points, it is possible to determinate the flexibility of the control system for a set of amounts of oil volume. Analyzing the stability of the oil level during the tests, it is realizable that the rotational speed has high influence on the control system. However, at the pre-testing speed (2250 $\mathrm{rpm}$ ) and the testing speed (3500 rpm), the controller maintained the oil level inside the maximum variation permissible of $\pm 3 \mathrm{~mm}$. By analyzing the step response of the controller, it is possible to say that the restrictions imposed were effective and the volume nonlinearities were no so relevant. Future analysis could be done regardless to the influence of the oil temperature in the system's dynamics and the rotation direction in the oil turbulence.

No longer, all proposed requirements were achieved, the controller proved to be effective in the oil volume controlling, has defined by the fatigue gear testing standards. What enables the presented test center to generate comparable results to similar test centers.

\section{REFERENCES}

[1] FZG, "Influence of Lubricant on the Pitting Capacity of Case Carburized Gears in Load-Spectra and Single-StageInvestigations," Technische Universität Müchen, 2010.

[2] Höhn, B., Michaelis, K., Otto. H. "Influence of immersion depth of dip lubricated gears on power loss, bulk temperature and scuffing load carrying capacity," International Journal of Mechanics and Materials Design, Volume 4: 2008.

[3] Petry-Johnson, T., Kahraman, A., Anderson, E., Chase, R. "An Experimental Investigation of Spur Gear Efficiency," ASME. Journal of Mechanical Design, 2008.

[4] GORLA, C.; et al. "Hydraulic losses of a gearbox: CFD analysis and experiments," Tribology International, Volume 66, 2013.

[5] Ogata, K. “Engenharia de Controle Moderno,” São Paulo, 2006. 